\title{
Saving Product Lives in Global and Local Remanufacturing Networks: A Scientific and Commercial Work Report and an Outlook
}

\author{
Prof. Dr.-Ing. Rolf Steinhilper (University of Bayreuth) and Chem. Eng. Alan Brent (University of Pretoria) \\ Rolf.Steinhilper@uni-bayreuth.de, abrent@eng.up.ac.za
}

\section{Theses to Characterize the Perspectives of Remanufacturing}

\begin{abstract}
Remanufacturing, which is becoming the standard term for recycling by manufacturing "good as new" products from used products in an industrial (series production) scale, looks back to an almost 65 year long history.

It started in the United States of America and in the United Kingdom of Great Britain in 1940 - the time when World War II fully occupied their industries with aircraft, tanks and weaponry manufacturing. While no private car (not to say spare parts) production existed in the US for five years in those times, remanufacturing obviously offered the only way to keep America's cars on the road.
\end{abstract}

Meanwhile, not only the world wars, but also the cold war belong to history and do not influence our industrial economies too much any more. Industrial production of private industrial products, whether it comes to cars, electric or electronic goods, does not at all suffer from undercapacity any more. In most areas, the ever-increasing productivity has led to overcapacities, making up to date products of the finest technology and performance available in any quantity and at even falling prices.

So, where is the chance and where is the future for remanufacturing under such economic circumstances? From the first authors' work for both the manufacturing and the remanufacturing sector over the past 25 years, extended by an international viewpoint in particular from the second author's research, the following work report and outlook about remanufacturing can be given in 10 theses:

\section{Markets and Legislation Both Drive Remanufacturing}

With current legislative initiatives like the European WEEE (Waste of Electric and Electronic Equipment) regulations and the IPP (Integrated Product Policy) green book discussions and their international and global counterparts one often considers industry`s (re)actions as an answer rather to the political agenda than to market pull. However, one must not forget that on the one hand customers` demands will always be the strongest driving forces in the markets in the long term - and that on the other hand industry`s strategies, methods and tools, which are developed in order to cope with environmental requirements, in many cases also have their applications - or even their origin from economic purposes.

If one looks at the modern concept of "Product Stewardship", this integrative approach along the product life cycle has originally been designed as an alliance of all developing parties involved already for a successful very first life-cycle-phase of a product (the "birth") with the aim of a shortest possible "Time to Market". Furthermore, Product Stewardship as an alliance between product and spare parts manufacturers, maintenance and support parties also saw a minimum "Total Cost of Ownership" and a perfect "Customer Relations Management" among their primary objectives both again already with quite some tradition. Thus, managing the entire product life cycle until its very end (or the "rebirth" of the product) just looks like the logical extension of a successful and to a certain extent already well established approach.

Future Product Stewardship from an environmental view point meets already classic challenges like product take back regulations and recycling responsibility, and will include coming challenges in the area of life-cycle-assessment obligations, recyclability and/or climate protection declarations to be presented for each new product intended for their respective markets.

So what's new? Critically reviewed at least two observations deserve mentioning: First, recent initiatives and activities of key role players, e.g. in the remanufacturing and reuse business, give indications that both economic and ecologic approaches exist even to close the gap between shorter innovation cycles and longer product lives like in the fast moving electric, mechatronic and electronic industry.

World Leaders in the relevant industries push forward their remanufacturing activities - and their public presence in this field. Second, therefore, there is a clear trend showing that not mainly reactions (to legislation and/or market developments) but action (towards the customer) is driving remanufacturing within the Integrated Product Policy. This new attitude is of course backed up - or required - by public policies, but 
primarily gives a brilliant example for a classic business success strategy formulated by the Italian car/star designers Pininfarina already in 1985: "The first gets the market - and sets the market. Today`s companies' intensified Remanufacturing Policies are designed to set the markets, not just get the markets, which are international markets anyway.

\section{Remanufacturing Reaches Global Dimensions}

Anyhow it is a common observation that today new concepts spread globally at higher speeds and with higher immediate levels of awareness in all important markets than they did five or ten years ago.

Also a new scientific publication today attracts more immediate attention, worldwide awareness and feedback than before the internet age.

But even keeping these facts a mind - and already getting used to them - it can be surprising at what high speeds a new concept becomes international and global even nowadays. Remanufacturing is such a concept. It shows continuous two digit growth rates now already since around five years or more precise: since the era of even shorter product innovation cycles and wider product varieties. These aspects had once been regarded as limiting (or killing) influences to the concept of remanufacturing, which by its nature is extending product lives and requiring some quantities of similar products. On the contrary, remanufacturing has experienced a turnaround (see thesis 5) and is now expanding to new applications (see thesis 3 to 7) and new international presences around the globe.

As an indicator for global awareness, it has surprised the author (not to say honoured and pleased), which recognition a recent book publication on remanufacturing once having been made available in a few major world languages, received in many a corner of the globe.

With comparably little supporting efforts by the publisher, the idea, the concept and the successful case studies of remanufacturing seem to appear just in the right time in the markets to be spread by themselves, to attract attention in different minds and cultures and to start demand for more editions and examples. Besides its clear economic and environmental benefits, there might of course be one general supportive element: As the "old" and brave economy has re-emerged from the shadows of the boom and bust New Economy, remanufacturing also suddenly finds itself in the spotlight. Remanufacturing, for so long the "Hidden Green Giant" about which only a few academics were aware a generation ago, is now attracting the attention of many scientists, executives, newsmakers, politicians. Remanufacturing is, indeed, reaching into more markets than ever before - touching upon all aspects of our society.

\section{Future Automotive Remanufacturing Mainly Challenged by Mechatronics and Electronics}

Remanufacturing has its strongest tradition and currently also its strongest representation in the automotive sector. Automotive products remanufacturing accounts for two thirds of all remanufacturing.

Listing just the most important of the various kinds of automotive units being remanufactured, one finds the whole range of units which stand for function, performance, safety and comfort in today's cars and trucks:

Modern cars and light trucks contain advanced electronic technology that monitors or controls virtually every function of the vehicle including: brakes, steering, air bags, fuel delivery, ignition, lubrication, theft prevention, emission controls and soon, tire pressure. It is necessary to have full access to the information, parts and tools necessary to accurately diagnose, repair, or re-program these systems.

So tomorrows remanufacturing companies will increasingly face the challenge of understanding and managing complex mechatronic systems like electronically controlled automatic transmissions, electrically (not hydraulically) assisted power steerings, electrically (not belt) driven water pumps, Integrated starter and alternator devices (so called ISAD) and so on. This will require them to become multidisciplinary experts, not mainly mechanical precision and electric competence performers.

It will still be a less difficult task, if the mechanic or hydraulic component and electric/electronic drive/control form one functional unit to be remanufactured. Here some intelligent "reverse engineering" to understand the unit is still possible. But when it comes to units who communicate with an electronically unit somewhere else in the car ( and not returning with the unit to be remanufactured) the remanufacturers needs the information content going back and forth. This requires in any case the remanufacturer access to information and specification data of the OEM.

To allow this, and to assure a free competition also in the automotive aftermarkets of the future, both in Europe and in the USA legislative initiatives are underway to ensure free access also for independent repairs and remanufacturers to the OEMs information data bases and training programmes. Thus, an "electronic sealing" of the products by the OEMs should be avoided. Anyhow, time advantage, more experience and background knowhow of the OEMs regarding electronic information within their units and components might to a certain 
extent still strengthen their position in future remanufacturing markets.

\section{Remanufacturing Increasingly Managing Safety and Reliability Issues}

In addition to the impressive activities in the automotive sector, technology development and market expanse in many more product and industry sectors are fruitful grounds for remanufacturing as well. In practice one can in fact find a nearly unlimited range of products being remanufactured in a wide range of applications.

The product spectrum reaches from machine tools and from mechanic to electronic products, industrial robots via copying machines and vending machines towards ATMs, up to computers and their parts as well as even cellular phones, which count as the most recent addition to remanufacturing in global scope and scale.

One research project underway in this application at the institutions of the two authors will be mentioned within thesis 7 later.

Although it is a matter of fact, that with state-ofthe-art technologies and quality assurance measures applied, including $100 \%$ inspection, the quality and reliability of remanufactured products is often higher than of similar new products inspected only by random sampling, these questions still play a key role in serious and often controversial discussions about the future of remanufacturing and reuse of parts.

Besides scientifically proven facts and experiences about failure rates, wear and stress theories and life expectations forecasts, there are also new and wide spread practical examples which help to clear the air in this important field.

On one hand, more and more aircraft get airborne in their very second - or third - lifetime. Aircraft overhaulings and modernizations - or conversions from passenger to freight liners with even higher take off weights than in their first use phase are becoming common businesses.

As everyone is aware, Aviation Authorities` quality certifications are the strictest to apply for. With every step from disassembly to reassembly, these processes are nothing else than straight forward remanufacturing. For the first time in their history, the US-SAE AMTC (Advanced Manufacturing Technology Conference) for the Aircraft Industry in 2002 saw a special session dedicated to remanufacturing and upcycling, underlining and strengthening/ extending this way of thinking and its respective technologies.

On the other hand, keeping ground contact, by using reliable breaks, rack and pinion steerings etc. which are relevant to any vehicle`s safety, also sees more and more remanufacturing successfully applied to this components.
The reliable technology and theory is available to a wide range of applications - so success factors will in the future more likely be associated with reliable organization and practical realization of applicable quality management systems and standards like ISO 9000 , in manufacturing and remanufacturing enterprises as well - soon also accompanied by the "brothers" and "sisters" from the ISO 14000 series, where applicable. Last but not least, with the current movements of extending warranty periods remanufactured parts enter their markets with the same two year warranty as new parts.

\section{Remanufacturing Becoming the Essential Strategy for Affordable Spare Parts}

The general observation is that remanufacturers both OEMs and independent market players - are now conquering new product areas and markets. In this they benefit from the fact that new product models are being launched every few years, as is a wider variety of housings, mechanic subassemblies, electric and electronic components. This makes it almost impossible, and certainly economically unfeasible for manufacturers to supply new spare parts after 5 to 10 years in service.

Choosing from the four strategies possible to offer spare parts for out of production products in the market:

- Manufacturing and storing the expected overall need/ quantity of spare parts at the end of product production on the original production lines (which can then be pulled down)

- Manufacturing of needed quantities in adequate batches of spare parts on the original production lines (kept operational for these purposes) from time to time

- Manufacturing of needed quantities in adequate spare parts on other flexible production equipment (if available - usually not for electronics) from time to time

- Remanufacturing of spare parts from old parts from other products retiring from the market, remanufacturing more and more offers the only affordable and appropriate strategy.

Otherwise cost for spare part availability in the product life cycle would be exploding and unmanageable. Consequently, it comes as no surprise that remanufacturers are finding renewed strength and entering into new alliances. 


\section{Reuse and Repair Concepts Celebrate a Rebirth}

With the tendencies already mentioned under the thesis before, new spare parts for a wide range of product varieties with short innovation cycles are becoming scarce or even unavailable, in any case to ensure their availability over years is causing considerable and increasing cost so that they arrive seemingly overpriced in their customers ' hands. As a consequence, not just remanufacturing, but also the direct reuse of parts enjoys the tailwinds of both economically and environmentally conscious market players in the transportation, electric and electronic industries and their respective products. Especially in the automotive market, also insurance companies step in - on one hand to cut costs for collision damage waiver packages by supporting accident repairs with used parts, where experts estimate possible annual savings of multi billions of Euros or Dollars for the worldwide automotive market alone. On the other hand, the reused parts' move out of the backyard image is also supported by insurance backed up warranties on used parts, where recently also automotive associations act as driving forces.

This applies to the so called developed countries (or the industrialized parts of the world), where new high products and parts falling off from highly automated production lines seemed to be available at more attractive prices (often far below of the labour cost of a working hour) and where affordable labour has been the bottleneck so far. Here a turnaround towards more repair and reuse originals from sudden, so far unexperienced problems with production possibilities for past product generations, technologies and parts at affordable prices.

In the not so much industrialized parts of the world, affordable labour force is available at almost every corner of the streets, while capacities, competences, technical information and skills for repair formed the major bottlenecks. Here also a turnaround towards new possibilities of repair and reuse originates from sudden, so far unexpected sources of information either via the internet or in written form, and coming from all regions of the world.

As an example, if one looks into markets and into the repair scene of Information and Communication Technology (ICT) products like TV sets, Personal Computers and cellular phones in a country like South Africa, the South African government has defined a specific sub-sector to the ICT sector, with the Standard Industrial Classification (SIC) code 62602, where an estimated 3000 businesses, i.e. one for every 15000 citizens, have been allocated to this sub-sector. This figure is still considered as an underestimate due to the strong presence of informal repair-service businesses in South African communities The relatively high prices of, for example, mobile units have resulted in a demand for repaired units in South Africa and other African countries, especially in rural and peripheral-urban communities, but the lack of detailed information has limited the actions that have been taken to develop this informal sector further.

This situation however is now improving, not to say already impressive in some applications.

Three ICT repair cases were considered in South Africa during July 2003:

- The repair of cellular or mobile units;

- The repair of home appliances, i.e. radios, Hi-Fi's, VCR's and television sets; and

- The repair of home computer systems.

Cellular phones are increasingly popular in the rural and peripheral communities of South Africa. However, the costs associated with owning these units often fall outside the budgets of individuals within these communities. If individuals do own cellular or mobile phones in rural and peripheral urban communities, the cost of new units (when a unit is out of order) and the distances (and cost of transportation) to central large repair facilities, justify the establishment of smaller repair businesses in these communities. A good example of such a typical business is P. Jones Cellulars, which is located in a shopping complex. The business was started in 1996, and is owned and managed, by 24 year-old Phillip (Philly) Jones Mataboge, who is also solely responsible for all the repair work. The total area of the business is approximately $20 \mathrm{~m}^{2}$, with half allocated to the sales of cellular phone accessories and the other half to cellular phone repairs. At least 40 cellular phones are repaired each month and a financial breakdown (of the repair part) of the business shows a minor share of labour cost and a major share of capital and parts cost.

Philly Mataboge employs two assistants that are responsible for the sales of the accessories and to purchase repair parts from central Pretoria (approximately $50 \mathrm{~km}$ by minibus taxi). Philly has had no formal training in cellular phone repairs, but his father did repair other household electronic equipment such as television sets, etc. and the basic skills were therefore passed along within the family. Repairs are often carried out while customers are waiting.

As cellular phone models change from time to time, and to be able to cope with these changes, P. Jones Cellulars is required to purchase cellular manual books in central Pretoria. These comprehensive manuals range in the price region of about the spare part cost of three or four industrial repairs and are therefore very affordable. The manuals, depending on the number of models included, provide detailed schematic diagrams of the different models, together with a description of the components that may be the cause of common problems (experienced by users). The manuals (and components) are currently purchased from another 
Pretoria store, which has a section allocated to cellular phones. These manuals (and components) are typically imported from China!!!

Comparable circumstances and available manuals characterize the situation also in the home appliance repair business like TV sets, HIFI stereos and videocassette recorders, which therefore will not be detailed at this point.

There is clear evidence however, that in todays connected world, technical information and training for skills in the repair sector can also be sourced successfully and with impressive quality from other places and continents than the OEM's sites.

\section{Remanufacturing Allows Multiple and Migratory Use of Products}

Increasingly one can observe new environment protection research programs, which top scientists, government authorities together with leading experts from the industry are designing for the future, trying to sponsor research work towards new environmentally manufacturing technologies including recycling and remanufacturing. They see future product cycles rather as intelligent networks than simple closed loops. Here tools to support the highest form of product and component reuse, the ability to provide documentation of all components and materials in a product as well as intelligent networks to multiple and migratory use of products and modules will be on top of the list. Not just the scientific community is in favour of such trends there are already existing industrial applications of considerable scale in today`s digital era: A very recent example is the exportation of surplus mother boards from a major European Computer OEM, via an independent expert broker, their conversion and rebirth as a key equipment part in hundreds of private regional digital $\mathrm{TV}$ recording and soon broadcasting studios all across the USA. This example of getting together different applications by multiple and migratory reuse of products is just one kind of integration approaches which can be observed and deserve support with different scales and scopes.

One research project underway at the institutions of the two authors for example focuses on cellular phones, which could have a multiple and migratory use with a first life in Europe, a second life after their remanufacturing in South Africa ... (meaning a migration from one continent to the other) - or a multiple and migratory use with a first life as a cellular phone, a second life as a wireless communication unit in a vending machine ordering new stock from the supplies automatically when its stocks are about to run out ...( meaning a migration from one application to the other).

\section{Product Cleaning Processes and Test Routines Require New Technologies Development}

The five steps of remanufacturing products in an industrial scale, assuring a constant quality level in a series production, follows the standardized sequence of

1) Disassembly of Product,

2) Cleaning,

3) Testing,

4) Reuse, Reconditioning or Replacement of Parts,

5) Reassembly of Product.

While steps 1), 4), and 5) still profit from valuable know-how and experiences from the manufacturing of new products, steps 2) and 3) in the near future will still require considerable research and development efforts towards new cleaning processes and test routines.

Cleaning processes, which are much more than washing away dirt and dust from the parts, but also de-greasing, de-rusting, de-oiling and freeing parts from old paint, have become more "environmentally friendly" in the past years, mainly by getting rid off from processes using ozone-layerdepleting chlorofluorocarbons (CFC's). The future will also need more "product friendly" and "material friendly" cleaning technologies - on one hand removing any unwanted layers from the parts' surfaces efficiently, on the other hand not interacting with more and more delicate products or difficult materials in new remanufacturing applications. A research project underway at the European authors' Remanufacturing Technology Center together with the partner institution in the USA deals with such new cleaning technologies, including supercritical carbondioxide cleaning processes. News on the results will be given in future reports.

Test Routines also offer new challenges for future remanufacturing products. How to assess the reusability of a car's airbag module? The development of new objective criteria besides the classic condition characteristics of components (line geometric dimensions and electric/electronic functionality) will become increasingly necessary.They must be supported wherever possible by lifetime monitoring devices built into the components of the future - as rather these data than an actual appearance of a product promise to forecast a reliable second life (or application) of a product. 


\section{Remanufacturing will Profit from Networking in Four Arenas.}

From Isolation to Integration - this vision drives networking and synergy efforts in the product life cycle chain in four arenas

- market participants

- products and applications

- neighbouring technologies

- international regions

Following the characteristics of its "Knots and Links", each network profits from main synergies, enjoys chances and strengths, as well as it can suffer from risks or weaknesses, which all deserve attention and action.

\section{Network of Participants:}

Knots and Links

OEMs, Remanufacturers, Dealers, Repair Shops, Rental (Car) Companies, Leasing Companies, Insurance Companies

Main Synergies

Product Cycle Market Development, Economic and

Ecologic Benefits

Chances, Strengths

High Growth Potential

Risks, Weaknesses

Competition vs. Cooperation

Network of Products and Applications:

Knots and Links

Consumer Products: Automotive Components, Electrics, Electronics, ...

Investment Goods:

Machine Tools, Motors, Manufacturing Equipment, Elevators, Aircraft, Mining Equipment, ...

Main Synergies

Sharing of New Technologies Development

Chances, Strengths

Cooperative Support for Product Cycles

Risks, Weaknesses

Lack of Communication

\section{Network of Neighbouring Technologies}

Knots and Links

Manufacturing, Remanufacturing, Repairing, Reusing, Recycling

Main Synergies

Best Choices for Product Life Extension

Chances, Strengths

Higher Customer Awareness for Product Cycles

Risks, Weaknesses

Quality of Second Hand Products, Image of Product

Life Cycle Technologies

\section{Network of International Regions}

Knots and Links

Western Europe, Eastern Europe, North America, Japan, Southeast Asia, Central/South America, South Africa
Main Synergies

Successful Cost Labour Management, Employment. Sufficient Product Supply also in Individual Regions with Limited Purchasing Power

Chances, Strengths

More than one Market. Global Efforts for the Environment

Risks, Weaknesses

Transport Efforts, Ecologic Bottom-line

\section{From Product Remanufacturing to Modernization Factories?}

While the supply chain side of a product's manufacturing cycle has seen considerable progress also with academic support to offer each customer his tailor made solution by successful approaches like mass customization technologies, the service and (still so called) "aftermarket-side" of the product life cycle still needs more brain forces dispatched towards successful solutions of integrated remanufacturing approaches, which are customer oriented, economically feasible and ecologically beneficial.

Here university education and applied research can be of valuable moderatory and methodological help and should further strengthen its roles not just on the manufacturing but also on the remanufacturing side.

This started in many institutions around the globe, where there is now more communication and cooperation than mainly confrontation because of competition.

So, if with further progress one looks for a vision beyond remanufacturing, the concept of "modernization factories", covering both existing and newly evaluated remanufacturing products, might lead to the exploration of new technological and organizational solutions.

As soon as the first results become available, report will be given, whether and how this light on the horizon recommends further steps towards modernization factories of today`s and tomorrow`s products. 